\title{
Heterogeneity and plasticity of T helper cells
}

\author{
Jinfang Zhu ${ }^{1}$, William E Paul ${ }^{1}$ \\ ${ }^{I}$ Laboratory of Immunology, National Institute of Allergy and Infectious Diseases, National Institutes of Health, Bethesda, MD \\ 20892, USA
}

CD4 $\mathrm{T}$ helper (Th) cells play critical roles in adaptive immune responses. They recruit and activate other immune cells including B cells, CD8 T cells, macrophages, mast cells, neutrophils, eosinophils and basophils. Based on their functions, their pattern of cytokine secretion and their expression of specific transcription factors, Th cells, differentiated from naïve CD4 $\mathrm{T}$ cells, are classified into four major lineages, Th1, Th2, Th17 and T regulatory (Treg) cells, although other Th lineages may exist. Subsets of the same lineage may express different effector cytokines, reside at different locations or give rise to cells with different fates, whereas cells from different lineages may secrete common cytokines, such as IL-2, IL-9 and IL-10, resulting in massive heterogeneity of the Th cell population. In addition, the pattern of cytokine secretion may switch from that of one lineage toward another under certain circumstances, suggesting that Th cells are plastic. Tregs are also more heterogeneous and plastic than were originally thought. In this review, we summarize recent reports on heterogeneity and plasticity of Th cells, and discuss potential mechanisms and implications of such features that $T h$ cells display.

Keywords: CD4, Tregs, T cell differentiation, transcription factors, cytokines

Cell Research (2010) 20:4-12. doi: 10.1038/cr.2009.138; published online 15 December 2009

Introduction of $\mathrm{T}$ helper $(\mathrm{Th})$ cell types and their functions

In response to an infection, a variety of cells of the innate and adaptive immune systems become activated and collaborate in the effort to control and eliminate invading pathogens. CD4 $\mathrm{T}$ cells (also known as Th cells) play critical roles during adaptive immune responses [1]. They help B cells to produce antibody and to undergo class switching and affinity maturation; they recruit and activate CD8 T cells, macrophages, neutrophils, eosinophils, basophils and other effector cells. They also directly act on many tissue cells, including epithelial cells and mucosal cells, during the process of pathogen clearance. The diverse functions of CD4 T cells are determined by their cytokine secretion patterns and their tissue locations.

Beginning in the $1980 \mathrm{~s}$, immunologists came to believe that different types of Th cells were involved in humoral and cell-mediated immune responses. In 1986, Coffman and Mosmann showed the existence of Th1 and

Correspondence: Jinfang Zhu ${ }^{\mathrm{a}}$, William E Paul ${ }^{\mathrm{b}}$

aE-mail: jfzhu@niaid.nih.gov

bE-mail: wpaul@niaid.nih.gov
Th2 clones differing from each other in the cytokines they produced [2]. Th1 cells mainly produce IFN $\gamma$, which is important for macrophage activation and clearance of intracellular pathogens, whereas Th2 cells produce IL-4, IL-5, IL-10 and IL-13, later shown to be critical for IgE production, eosinophil recruitment and clearance of extracellular parasites $[3,4]$. Th1 and Th2 cells are also involved in many diseases. Th1 cells were thought to cause many organ-specific autoimmune diseases, whereas $\mathrm{Th} 2$ cells are responsible for asthma and other allergic reactions.

With the discovery of IL-23, which shares the subunit p40 with IL-12, it became clear that many autoimmune diseases, earlier attributed to Th1 cells, are indeed induced by other Th cells that are IL-23 responsive [5]. Soon, this lineage of Th cells was identified as Th17 cells, which produce many cytokines including IL-17a, IL-17f, IL-22 and IL-21 [6, 7]. In addition to their involvement in autoimmune diseases, Th17 cells also play critical roles during immune responses against extracellular bacteria and fungi [8].

Naturally occurring regulatory $\mathrm{T}$ cells (nTregs) develop in the thymus [9]. IL-2 and TGF $\beta$ signaling, as well as CD28 co-stimulation and self-recognition seem to be important for nTreg generation. At essentially the same 


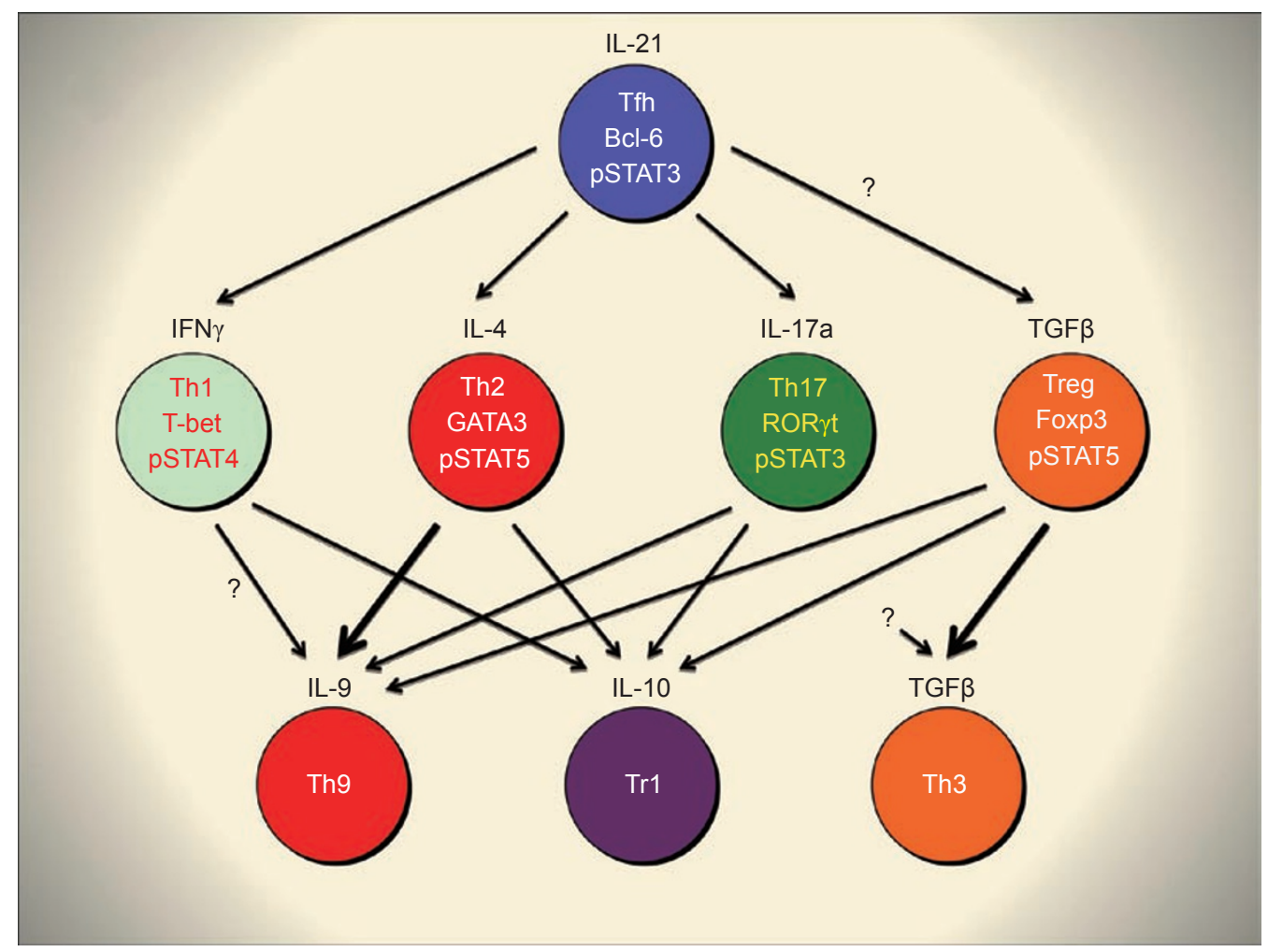

Figure $1 \mathrm{~T}$ helper lineages and subsets. CD4 T helper cells can be divided into at least four lineages, namely, Th1, Th2, Th17 and Treg. These cells express master transcription factors (shown inside the cells, pSTATs stands for phosphorylated active STATs) and secrete signature cytokines (shown on the top of the cells). Other 'lineages', including Th3, Tr1, Tfh and Th9 cells, have been proposed. However, different Tfh cells also produce Th1, Th2, Th17 or Treg cytokines, whereas some Th1, Th2, Th17 and Treg subsets secrete Th9, Tr1 or Th3 'signature' cytokines,IL-9, IL-10 or TGF $\beta$, respectively, as shown by arrows. Therefore, Tfh, Th9, Tr1 and Th3 cells may represent subsets of Th1, Th2, Th17 and Treg lineages.

time that Th17 cells were discovered, it was shown that treatment of naïve peripheral CD4 T cells with a TCR stimulant and with TGF $\beta$ plus IL-2 caused the appearance of inducible regulatory $\mathrm{T}$ cells (iTregs) [10]. The Treg population found in vivo consists of both nTregs and iTregs, both of which express transcription factor Foxp3. Like nTregs, iTregs may also be involved in selftolerance, immune modulation and promoting immune responses under certain circumstances [11].

Thus far, four CD4 Th cell lineages are generally recognized, namely, Th1, Th2, Th17 and Treg cells [1]. The cytokine environment during priming and the consequent activation of specific transcription factors are two key elements controlling Th cell differentiation from naïve CD4 T cells. A distinct set of cytokines promotes the differentiation processes for each lineage: IL-12/IFN $\gamma$ for Th1; IL-4/(IL-2, IL-7, TSLP) for Th2; TGFß/(IL-6, IL21, IL-23) for Th17 and TGF $\beta /$ IL-2 for Tregs. The transcription factors that govern the differentiation of these cells are also well defined: T-bet/Stat4 for Th1, GATA3/ Stat5 for Th2, ROR $\gamma \mathrm{t} / \mathrm{Stat} 3$ for Th17 and Foxp3/Stat5 for
Tregs.

Other potential Th cell 'lineages' have been proposed including Th3 cells $[12,13]$ (TGF $\beta$-producing CD4 T cells), Tr1 cells [14] (IL-10-producing CD4 T cells), Th9 cells $[15,16]$ (IL-9-producing CD4 T cells) and Tfh cells [17-19] ( $\mathrm{T}$ follicular helper $(\mathrm{Tfh})$ cells located in the follicular regions of lymph nodes and spleen). Since the 'signature' cytokines produced by these Th cells are also the products of $\mathrm{Th} 1 / \mathrm{Th} 2 / \mathrm{Th} 17 / \mathrm{Treg}$ cells and the transcription factors they express are not unique, whether these cells represent lineages separate from the known four lineages is uncertain and needs further investigation. The relationships between Th1/Th2/Th17/Treg and Th3, Tr1, Th9, Tfh cells are shown in Figure 1.

\section{Th 'lineages' other than Th1/Th2/Th17/Treg?}

\section{Th3 cells or TGF $\beta$-producing cells}

Oral tolerance induces TGF $\beta$-producing cells, which have been designated as Th3 cells [13]. However, TGF $\beta$ can be produced by most activated Tregs. The membrane 
bound form of TGF $\beta$, associated with latency-associated peptide (LAP), can be detected on the surface of many Tregs $[20,21]$. LAP has been found on the surface of some $\mathrm{CD} 4^{+} \mathrm{CD} 25^{-}$cells, which are also capable of suppressing colitis [22]; $40 \%$ of such cells express Foxp3 [21], implying that they are also Tregs. It now has been proven that oral tolerance induces $\mathrm{CD} 4{ }^{+} \mathrm{CD} 25^{+}$cells that express CTLA-4, TGF $\beta$ and IL-10 [23], as well as Foxp3 [24]. Therefore, the population of cells designated as Th3 contains a large proportion of iTregs.

Some Th3 clones also produce IL-4 and IL-10; however, those clones that produce the highest levels of TGF $\beta$ fail to produce IL-4 or IL-10 [12]. Since $~ 60 \%$ of $\mathrm{CD} 4^{+} \mathrm{CD} 25^{-} \mathrm{LAP}^{+}$cells do not express Foxp3 [21], this suggests that Th cells, other than Tregs, can produce TGF $\beta$. However, the function of TGF $\beta$-producing Foxp3-negative cells has not been studied. TGF $\beta$, in combination with IL-2, has been shown to induce B cells to switch to expression and production of $\operatorname{IgA}$ [25]. Whether the TGF $\beta$ that is produced by CD4 T cells is important for IgA switching is unknown. If that were to be the case, then the TGF $\beta$-expressing CD4 $\mathrm{T}$ cells that are responsible for IgA switching could be designated as 'real' Th3 cells.

\section{Tr1 cells or IL-10-producing cells}

IL-10 was initially recognized as a Th2 cytokine [2]. It was then reported that some cells with regulatory functions express IL-10 and such cells were designated Tr1 cells [14]. However, some 'conventional' Tregs also produce IL-10, and IL-10 production by these cells is important for controlling inflammation in the gut [26]. Nonetheless, it appears that $\operatorname{Tr} 1$ cells are different from Foxp $3^{+}$IL-10-producing cells [27]. However, the situation is complicated by the finding that IL-10 production is also found in subsets of Th17 cells and Th1 cells [2830], and that IL-10 production by Th17 and Th1 cells negatively regulates their function. Indeed, in such cells, strong TCR stimulation, which leads to sustained Erk activation, results in IL-10 production [31], suggesting that IL-10 serves as a critical negative feedback regulator to control the magnitude of many types of immune responses and to prevent tissue damage. Therefore, $\operatorname{Tr} 1$ cells may very well not be a separate lineage, but include both IL-10-producing Trges, as well as those subsets of Th1, Th2 and Th17 cells that are capable of expressing IL-10.

\section{Th9 cells or IL-9-producing cells}

IL-9 was first recognized as a Th2 cytokine [32]; introduction of a GATA3-encoding retrovirus or a retrovirus encoding a constitutively active form of STAT5 can induce cells to be competent to produce IL-9 [33]. However, IL-9 expression is also inducible by TGF $\beta$ stimulation [34]. Indeed, TGF $\beta$ can induce competence to produce IL- 9 by differentiated Th2 cells, while the expression of IL-4 is suppressed in such cells $[15,16]$. TCR stimulation of naïve CD4 T cells in the presence of TGF $\beta$ plus IL-4 can also induce cells competent to produce IL9. It has been proposed that such IL-9-producing cells be designated as Th9 cells. However, IL-9 production is not unique to such cells. Tregs and Th17 cells also express IL-9 [35-37]. In addition, just as IL-10 production in Th2 cells depends on GATA3, our unpublished data suggest that induction of IL- 9 competence by TGF $\beta$ and IL-4 requires GATA3 expression. Therefore, IL-9-producing cells may represent subsets of known Th lineages including Th2, iTreg and Th17 cells. It is unknown whether Th1 cells can express IL-9 under certain circumstances.

\section{Tfh cells or follicular Th1/Th2/Th17 cells}

Tfh cells were initially proposed as a separate lineage based on their failure to express Th1/Th2/Th17 cytokines and lineage-specific transcription factors [17-19]. However, recent reports showed that Tfh cells developed in vivo during Th1, Th2 or Th17 immune responses may express IFN $\gamma$, IL-4 or IL-17a [38-41]. Therefore, Tfh cells seem to be heterogeneous and to have a close relationship to Th1, Th2 or Th17 cells. Although Tfh cells express high levels of Bcl-6 and Bcl-6 is critical for Tfh cell development [42-44], the involvement of other lineage-specific transcription factors, including T-bet and GATA-3, in such cytokine-secreting Tfh cells has not been determined. However, based on the data from GATA3 conditional knockout mice, GATA3 is absolutely required for IL-4 production and IgE synthesis in vivo [45], suggesting that the IL-4-secreting Tfh cells also depend on GATA 3 and that GATA 3 is expressed in such cells at least at basal levels, which may be sufficient to induce IL-4 production. Therefore, Tfh cells may represent a particular state of Th1, Th2 or Th17 cells, particularly those Th1/Th2/Th17 cells that migrate to the B-cell follicle. However, the alternative possibility is that naïve CD4 $\mathrm{T}$ cells differentiate into Tfh cells on certain forms of stimulation and then they acquire IL-4-, IFN $\gamma$ - or IL17-producing capacity. Interestingly, in the gut, Tfh cells mainly originate from Tregs [46]. Further careful analyses on the subsets of Tfh cells and their patterns of gene expression and epigenetic modification may allow deeper insights into understanding the relationship between $\mathrm{Tfh}$ and Th1/Th2/Th17/Treg cells.

\section{Memory-like CD4 cells}

After the peak of an immune response, memory Th 
cells start to be generated following massive death of effector cells. In C57BL/6 mice, CD44 is a marker for memory T cells. Most CD8 memory T cells express high levels of IL-2R $\beta$ and rely on IL-15 for their survival and expansion [47]. In the lymph nodes of naïve mice, the CD8 memory phenotype cells are largely CD62Lexpressing cells, which is similar to that of authentic antigen-specific central CD8 memory cells. By contrast, only a minority of lymph node CD4 memory (CD44 $4^{\text {bright }}$ ) cells expresses CD62L and IL-2R $\beta$. It has been reported that those antigen-specific antiviral CD4 memory cells that have a slow turnover rate require IL-15 for their survival and proliferation [48], suggesting that the more rapidly turning over $\mathrm{CD} 4^{+} \mathrm{CD} 44^{\mathrm{hi}} \mathrm{IL}-2 \mathrm{R} \beta^{\text {low }}$ cells represent a special population different from the bona fide memory cells. The functions of these memory-like CD4 T cells have not been determined.

\section{Heterogeneity among Th1/Th2/Th17 cells}

Each Th lineage is able to produce more than one cytokine. However, individual cells within same lineage may display different patterns of cytokine production. Indeed, most of the stimulated cells express one, two or three but rarely all of the cytokines that the lineage can produce. For example, Th1 cells are able to express IFN $\gamma, \mathrm{LT} \alpha$, IL-2 and TNF $\alpha$, but only a limited proportion of Th1 cells are able to express all these cytokines at the same time [49]. As mentioned above, some Th1 cells can acquire IL-10-producing capability, while IFN $\gamma$ production is maintained. Similarly, Th2 cytokines, IL-4, IL5, IL-13 and possibly IL-25 are expressed differently at single-cell level and an individual Th17 cell may express any combination of Th17 cytokines, including IL-17a, IL-17f, IL-21 and IL-22. In some cases, the differential pattern of cytokine production by individual cells may be determined by stochastic formation of a transcriptional complex of NFAT with other factors at a particular cytokine locus, as well as by the differential states of epigenetic modification of the cytokine loci [50].

Differential expression of some transcription factors may also be responsible for the heterogeneity among a certain lineage. For example, PU.1 expression is enriched in those Th2 cells that fail to produce IL-4 [51]. It is also possible that the amounts of GATA3 expression in individual cells influence their ability to preferentially express either IL-4 or IL-13. Th17 cells express high levels of both ROR $\gamma t$ and the aryl hydrocarbon receptor AhR [52]; however, whether these two molecules are co-expressed in every Th17 cell or AhR expression is limited to Th17 cells capable of producing IL-22 is not known. As discussed above, the combined expression of
Bcl-6 with the 'master' Th1/Th2/Th17 transcription factors, T-bet, GATA3 and ROR $\gamma \mathrm{t}$, may determine the ability of Tfh cell to produce IFN $\gamma$, IL-4 or IL-17.

\section{Heterogeneity of regulatory $T$ cells}

Tregs consist of nTregs (developed in the thymus) and iTregs (induced from naïve CD4 $\mathrm{T}$ cells in the periphery). So far, no reliable marker has been shown to distinguish iTregs from nTregs. A total of $20-30 \%$ of the Tregs in a normal animal express CD103 [53, 54]. These $\mathrm{CD} 103^{+}$Tregs display an activated phenotype and have higher suppressive activity. Most iTregs induced in vitro and those Tregs found in inflamed brain express CD103 [55]. Whether CD103 is a marker for iTregs in vivo is not clear.

The master transcription factors T-bet, GATA3 and ROR $\gamma \mathrm{t}$, are also expressed by subsets of regulatory $\mathrm{T}$ cells, suggesting that Tregs are more complex than were originally thought. In studying the relationship between Th17 cells and iTregs, it was initially found that many differentiating cells co-express ROR $\gamma t$ and Foxp3, and such cells were considered to be the progenitors of either Th17 or iTregs [56]. However, IL-6-stimulated nTregs express ROR $\gamma \mathrm{t}$ and IL-17 [57, 58], suggesting that some ROR $\gamma$ t-expressing Tregs found in vivo may have originated from nTregs. T-bet-expressing Tregs, which express CXCR3, exist in normal mice. T-bet-deficient Tregs proliferate less well in a Th1 inflammatory environment and fail to suppress Th1-related autoimmune diseases [59]. Our unpublished data indicate that GATA3 is expressed in both nTregs and iTregs, although its function in Tregs needs to be further characterized.

\section{Plasticity of Th1/Th2 cells}

Th2 cells can be induced by IL- 12 to produce IFN $\gamma$. On the other hand, differentiated Th1 cells fail to express IL-4 even when they are re-stimulated under Th2 culture conditions. The plasticity of Th1/Th2 cells seems to depend on their differentiation state [60]. The further the cells differentiate, the harder it is to alter their cytokine production profile. Therefore, although fully differentiated Th1 cells cannot turn on IL-4 expression, Th1 cells primed in vitro for one round (that is, $\sim 1$ week) were able to produce IL-4 when they were switched to Th2 culture conditions [45]. The existence of IFN $\gamma^{+} \mathrm{IL}-4^{+}$cells in such cultures implies that partially differentiated Th1 cells retain their capability to become IL-4-producing cells. Similarly, despite the report that Th2 cells could gain the capability to produce IFN $\gamma$ when they are stimulated through IL-12, our unpublished data suggest that 
most fully differentiated Th2 cells, that is, those obtained after 3-4 rounds of in vitro Th2 priming, fail to produce IFN $\gamma$, which correlated with the failure of T-bet induction in these cells. A small proportion of these Th2 cells that have been primed for 3-4 rounds do upregulate T-bet and IFN $\gamma$; however, such cells may represent partially differentiated Th2 cells.

The expression of two Th2 transcription factors, GATA3 and Gfi-1, is required to maintain Th2 phenotype. Gata 3 deletion in Th2 cells results in IFN $\gamma$ production [45] and the induction of IFN $\gamma$ in these cells is due to a T-bet-independent activation of the Runx3-Eomes pathway (our unpublished data), which is predominantly used by CD8 T cells for IFN $\gamma$ production. Active epigenetic modifications at Rorc, Il23r and Cd103 loci are detected in Gfi-1-deficient Th2 cells, suggesting that Gfi-1 is not only important for Th2 cell expansion but also for suppressing Th17 and iTreg differentiation [55].

It is very difficult to redirect Th1 and Th2 cells to become either Th17 or Treg cells, consistent with suppressive genomic modifications at Rorc and Foxp3 loci in Th1 and Th2 cells [61]. However, when TGF $\beta$ is given to Th2 cells, IL-4 production is suppressed, while IL-9 is induced $[15,16]$. Our preliminary data suggest that GATA3 and Gfi-1 may play important roles in such transition of cytokine production.

\section{Plasticity of Th17/Treg cells}

IL-17-producing cells are relatively unstable with regard to their cytokine-producing phenotype compared to Th1 and Th2 cells. On transfer, purified IL-17-producing cells acquire the capacity to make IFN $\gamma$ in a STAT4and T-bet-dependent manner [62]. Our unpublished data showed that even after 5-6 rounds of Th17 priming, when more than $90 \%$ of such cells could produce IL-17, IL-12 induces these cells to produce IFN $\gamma$ and IL-4 induces them to be competent to produce IL-4, while they maintain IL-17 expression. Thus, Th17 cells are plastic throughout their entire differentiation stage. It has been well documented that IFN $\gamma^{+} \mathrm{IL}-17^{+}$cells exist in vivo. The existence of IL- $4^{+} \mathrm{IL}-17^{+}$cells has not been reported; however, it is likely that such cells exist. The importance of the Th17 cells switching to Th1 or Th2 phenotype has not been determined. It is interesting to note that many Th1 and Th2 responses, including those mediating autoimmune diseases and allergic reactions, also require Th17 cells, partly due to their role in neutrophil recruitment as well as tissue inflammation.

Some Th17 memory cells have been shown to be stable in vivo [63]. Therefore, it remains possible that some subsets of Th17 cells may become terminally differenti- ated.

When cultured under Th1 conditions [61] or in a Th1biased inflammatory environment such as that induced by $T$. gondii infection, Foxp3-expressing Tregs can also produce IFN $\gamma[61,64]$. The expression of IFN $\gamma$ correlated with the upregulation of T-bet in these cells. Therefore, although IFN $\gamma$ is the Th1 signature cytokine, each of the other lineages retains the capacity to produce it. The plasticity of non-Th1 cells in producing IFN $\gamma$ may be explained by the bivalent H3K4 and H3K27 modification of the Tbx21 gene in Th cells other than Th1, including Th17 and Tregs [61]. In addition, the chromatin accessibility of the Ifng locus at CNS-22 in non-Th1 cells may also contribute to such flexibility $[65,66]$.

Dong and his colleagues [57] have reported that Tregs can become IL-17-producing cells when they are cultured with IL-6 and this correlates with their upregulation of ROR $\gamma$ t. Strober's group [58] also reported that Tregs can be self-induced to become IL-17-producing cells in the absence of TGF $\beta$ when IL- 6 is present. Similarly, other studies showed the existence of IL-17-producing Foxp3 cells, both in mice and humans [67, 68]. Transferring Tregs into a lymphopenic host also results in downregulation of Foxp3 accompanied by the production of IL-17 and IFN $\gamma$ [69].

Reduced expression of Foxp3 in Tregs by genetic means results in the acquisition of Th2 phenotype [70]. In addition, Tregs may become Tfh cells in the gut, as discussed earlier [46]. By using Foxp3-Cre to mark cells expressing or having expressed Foxp3, Bluestone and his colleagues [71] reported that many effector cells have previously expressed Foxp3, and thus are derived from Tregs, although a transient expression of Foxp3 during effector cell differentiation may also contribute to this finding.

\section{Relationship between heterogeneity and plasticity}

Th cells are heterogeneous and plastic. Heterogeneity comes not only from distinct Th lineages but also from many subsets within a same lineage and cells at different development stages. Plasticity reflects the cells' capability to switch from one lineage to another or to a mixed phenotype.

Cell plasticity may be relevant to cell heterogeneity. Even within a 'pure' differentiating population, individual cells respond differently. Therefore, some cells may represent fully differentiated cells that have lost plasticity, whereas others may retain the flexibility to switch due to their partial differentiation state. This is especially applicable to Th1 and Th2 cells (Figure 2).

It seems that most of the Th17 cells remain plastic, 


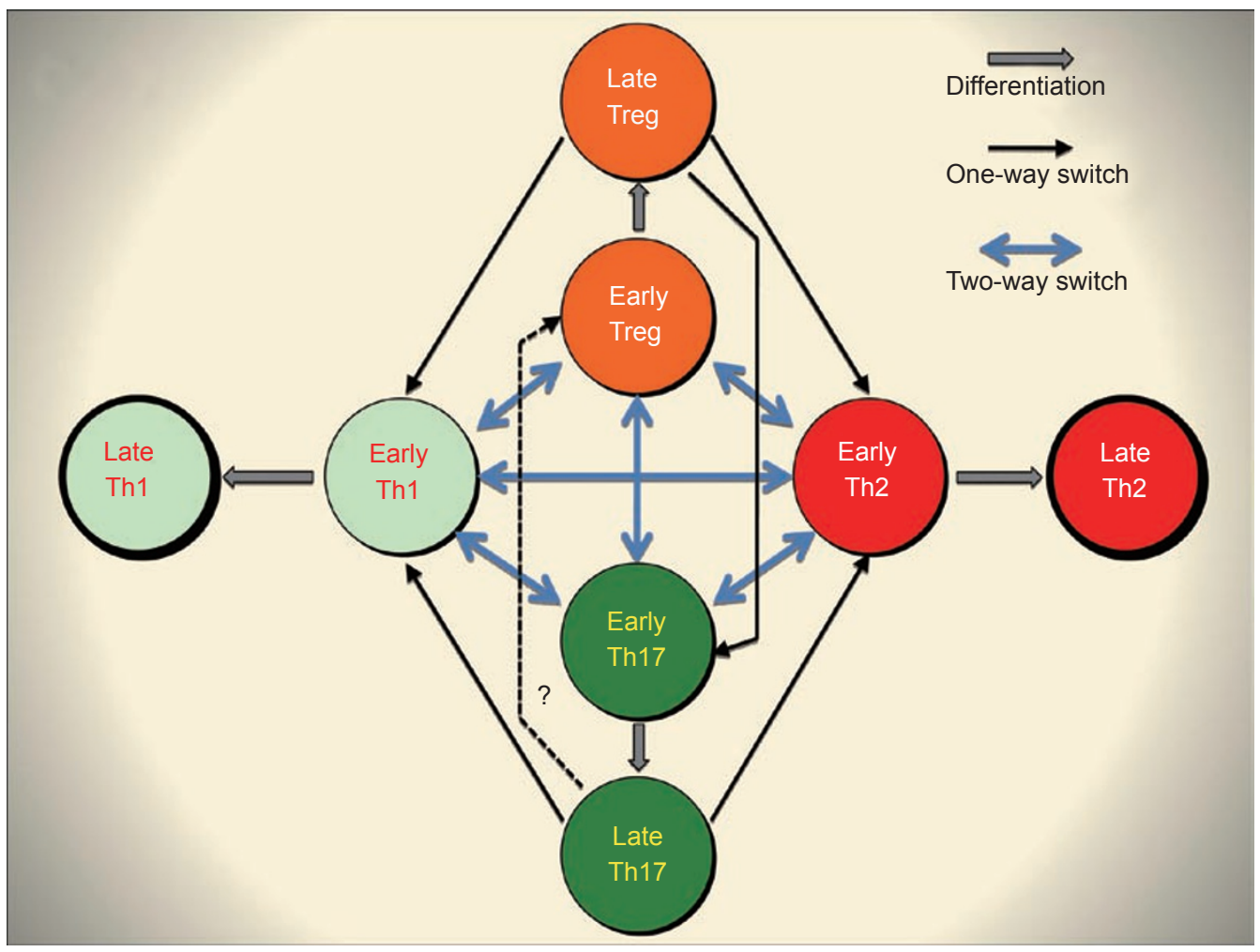

Figure 2 Plasticity of T helper cells. CD4 T helper cell plasticity depends on the differentiation state and cell types. At early stages of Th differentiation, each lineage can be easily redirected to other directions. However, at later stages, most Th1 and Th2 cells are terminally differentiated and cannot be switched, whereas the majority of Th17 and Treg cells remain plastic throughout their differentiation process.

since majority of the 'fully differentiated' Th17 cells are able to upregulate the master regulators of other lineages, including T-bet and GATA3, and to co-express IL-17/ IFN $\gamma$ or IL-17/IL-4.

IFN $\gamma$ and IL-17 can also be induced in Tregs correlated with upregualtion of T-bet and ROR $\gamma \mathrm{t}$, suggesting that a large proportion of Tregs are plastic. However, since there is no marker to distinguish nTregs from iTregs, it is difficult to determine whether both are plastic. It has been shown that iTregs, but not nTregs, lose Foxp3 when TGF $\beta$ is removed during restimulation [72] and human $\mathrm{CD}_{45 \mathrm{RA}^{+} \mathrm{Foxp}^{+} \text {cells are more stable than CD45RA }}$ Foxp $3^{+}$cells in maintaining Foxp3 expression [73]. On the other hand, another report showed that iTregs generated by TGF $\beta$ plus IL-2 stimulation are resistant to IL-6mediated Th17 conversion [74].

\section{What heterogeneity and plasticity mean to immune modulation}

In conclusion, Th cells are heterogeneous and somewhat plastic. Many Tregs, just like naïve CD4 T cells, can be differentiated into various types of Ths. Th17 cells are more plastic than Th1/Th2 cells, suggesting that Th17 cells may represent cells that are not terminally differentiated. Alternatively, Th17 cells may continue to express important molecule(s) in determining cell plasticity, which presumably have been repressed in fully differentiated Th1/Th2 cells. At early stages of Th cell differentiation or within certain subsets that are partially differentiated, CD4 T cells can be reprogramed into different lineages on receiving appropriate stimulus. Understanding the mechanisms, through which reprograming one Th cell type to another and then stabilizing the resulting phenotype can be achieved, has enormous implications for immune intervention.

An alternative strategy may be reprograming terminally differentiated antigen-specific CD4 T cells with certain phenotype into earlier progenitors, such as hematopoietic stem cells, naïve CD4 T cells or partially differentiated cells with plasticity, and re-differentiating such cells to a desirable Th effector population. As little as four transcription factors, namely, Oct4/Klf4/Sox $2 / \mathrm{Myc}$, are able to reprogram terminally differentiated fibroblasts into 
inducible pluripotent stem cells $[75,76]$. Klf4 is highly expressed in naïve $\mathrm{T}$ cells, but is downregulated during T-cell activation [77]. Finding other critical transcription factors that are highly expressed in naïve cells but are downregulated during T-cell differentiation, may allow the construction of combinations of transcription factors that could reprogram the differentiated Th cells back to naïve stage. Research in such dedifferentiation and redifferentiation holds great promise for future treatment of multiple immune-related human diseases, including autoimmunity, asthma and other allergic diseases, chronic infections and cancer.

\section{Acknowledgments}

This work is supported by the Division of Intramural Research, National Institute of Allergy and Infectious Diseases, National Institutes of Health, USA.

\section{References}

1 Zhu J, Paul WE. CD4 T cells: fates, functions, and faults. Blood 2008; 112:1557-1569.

2 Mosmann TR, Cherwinski H, Bond MW, Giedlin MA, Coffman RL. Two types of murine helper T cell clone. I. Definition according to profiles of lymphokine activities and secreted proteins. J Immunol 1986; 136:2348-2357.

3 Ansel KM, Djuretic I, Tanasa B, Rao A. Regulation of Th2 differentiation and I14 locus accessibility. Annu Rev Immunol 2006; 24:607-656.

4 Szabo SJ, Sullivan BM, Peng SL, Glimcher LH. Molecular mechanisms regulating Th1 immune responses. Annu Rev Immunol 2003; 21:713-758.

5 Cua DJ, Sherlock J, Chen Y, et al. Interleukin-23 rather than interleukin-12 is the critical cytokine for autoimmune inflammation of the brain. Nature 2003; 421:744-748.

6 Harrington LE, Hatton RD, Mangan PR, et al. Interleukin 17-producing $\mathrm{CD}^{+}$effector $\mathrm{T}$ cells develop via a lineage distinct from the $\mathrm{T}$ helper type 1 and 2 lineages. Nat Immunol 2005; 6:1123-1132.

7 Park H, Li Z, Yang XO, et al. A distinct lineage of CD4 T cells regulates tissue inflammation by producing interleukin 17. Nat Immunol 2005; 6:1133-1141.

8 Weaver CT, Hatton RD, Mangan PR, Harrington LE. IL-17 family cytokines and the expanding diversity of effector $\mathrm{T}$ cell lineages. Annu Rev Immunol 2007; 25:821-852.

9 Sakaguchi S. Naturally arising $\mathrm{CD}^{+}$regulatory $\mathrm{t}$ cells for immunologic self-tolerance and negative control of immune responses. Annu Rev Immunol 2004; 22:531-562.

10 Chen W, Jin W, Hardegen N, et al. Conversion of peripheral $\mathrm{CD} 4^{+} \mathrm{CD} 25^{-}$naive $\mathrm{T}$ cells to $\mathrm{CD} 4^{+} \mathrm{CD} 25^{+}$regulatory $\mathrm{T}$ cells by TGF- $\beta$ induction of transcription factor Foxp3. J Exp Med 2003; 198:1875-1886.

11 Curotto de Lafaille MA, Lafaille JJ. Natural and adaptive foxp $3^{+}$regulatory $\mathrm{T}$ cells: more of the same or a division of labor? Immunity 2009; 30:626-635.

12 Chen Y, Kuchroo VK, Inobe J, Hafler DA, Weiner HL. Regu- latory T cell clones induced by oral tolerance: suppression of autoimmune encephalomyelitis. Science 1994; 265:1237-1240.

13 Weiner HL. Induction and mechanism of action of transforming growth factor- $\beta$-secreting Th3 regulatory cells. Immunol Rev 2001; 182:207-214.

14 Groux H, O'Garra A, Bigler M, et al. A CD4 ${ }^{+}$T-cell subset inhibits antigen-specific T-cell responses and prevents colitis. Nature 1997; 389:737-742.

15 Veldhoen M, Uyttenhove C, van Snick J, et al. Transforming growth factor- $\beta$ 'reprograms' the differentiation of T helper 2 cells and promotes an interleukin 9-producing subset. Nat Immunol 2008; 9:1341-1346.

16 Dardalhon V, Awasthi A, Kwon H, et al. IL-4 inhibits TGF$\beta$-induced Foxp ${ }^{+}$T cells and, together with TGF- $\beta$, generates IL- $9^{+}$IL-10 $0^{+}$Foxp $3^{-}$effector T cells. Nat Immunol 2008; 9:1347-1355.

17 King C, Tangye SG, Mackay CR. T follicular helper (TFH) cells in normal and dysregulated immune responses. Annu Rev Immunol 2008; 26:741-766.

18 Vogelzang A, McGuire HM, Yu D, Sprent J, Mackay CR, King C. A fundamental role for interleukin-21 in the generation of T follicular helper cells. Immunity 2008; 29:127-137.

19 Nurieva RI, Chung Y, Hwang D, et al. Generation of T follicular helper cells is mediated by interleukin-21 but independent of $\mathrm{T}$ helper 1, 2, or 17 cell lineages. Immunity 2008; 29:138149.

20 Nakamura K, Kitani A, Strober W. Cell contact-dependent immunosuppression by $\mathrm{CD} 4{ }^{+} \mathrm{CD} 25^{+}$regulatory $\mathrm{T}$ cells is mediated by cell surface-bound transforming growth factor beta. $J$ Exp Med 2001; 194:629-644.

21 Chen ML, Yan BS, Bando Y, Kuchroo VK, Weiner HL. Latency-associated peptide identifies a novel $\mathrm{CD} 4{ }^{+} \mathrm{CD} 25^{+}$regulatory $\mathrm{T}$ cell subset with TGF $\beta$-mediated function and enhanced suppression of experimental autoimmune encephalomyelitis. $J$ Immunol 2008; 180:7327-7337.

22 Oida $\mathrm{T}$, Zhang X, Goto $\mathrm{M}$, et al. $\mathrm{CD} 4^{+} \mathrm{CD} 25^{-} \mathrm{T}$ cells that express latency-associated peptide on the surface suppress $\mathrm{CD} 4{ }^{+} \mathrm{CD} 45 \mathrm{RB}$ high-induced colitis by a TGF- $\beta$-dependent mechanism. J Immunol 2003; 170:2516-2522.

23 Zhang X, Izikson L, Liu L, Weiner HL. Activation of $\mathrm{CD} 25^{+} \mathrm{CD} 4{ }^{+}$regulatory $\mathrm{T}$ cells by oral antigen administration. J Immunol 2001; 167:4245-4253.

24 Mucida D, Kutchukhidze N, Erazo A, Russo M, Lafaille JJ, Curotto de Lafaille MA. Oral tolerance in the absence of naturally occurring Tregs. J Clin Invest 2005; 115:1923-1933.

$25 \mathrm{Kim} \mathrm{PH}$, Kagnoff MF. Transforming growth factor-beta 1 is a costimulator for IgA production. J Immunol 1990; 144:34113416.

26 Rubtsov YP, Rasmussen JP, Chi EY, et al. Regulatory T cellderived interleukin-10 limits inflammation at environmental interfaces. Immunity 2008; 28:546-558.

27 Roncarolo MG, Gregori S, Battaglia M, Bacchetta R, Fleischhauer K, Levings MK. Interleukin-10-secreting type 1 regulatory T cells in rodents and humans. Immunol Rev 2006; 212:28-50.

28 McGeachy MJ, Bak-Jensen KS, Chen Y, et al. TGF- $\beta$ and IL-6 drive the production of IL-17 and IL-10 by T cells and restrain T(H)-17 cell-mediated pathology. Nat Immunol 2007; 8:13901397. 
29 Jankovic D, Kullberg MC, Feng CG, et al. Conventional Tbet ${ }^{+}$Foxp $3^{-}$Th1 cells are the major source of host-protective regulatory IL-10 during intracellular protozoan infection. $J$ Exp Med 2007; 204:273-283.

30 Anderson CF, Oukka M, Kuchroo VJ, Sacks D. CD4 CD25 Foxp $3^{-}$Th1 cells are the source of IL-10-mediated immune suppression in chronic cutaneous leishmaniasis. J Exp Med 2007; 204:285-297.

31 Saraiva M, Christensen JR, Veldhoen M, Murphy TL, Murphy KM, O'Garra A. Interleukin-10 production by Th1 cells requires interleukin-12-induced STAT4 transcription factor and ERK MAP kinase activation by high antigen dose. Immunity 2009; 31:209-219.

32 Temann UA, Geba GP, Rankin JA, Flavell RA. Expression of interleukin 9 in the lungs of transgenic mice causes airway inflammation, mast cell hyperplasia, and bronchial hyperresponsiveness. J Exp Med 1998; 188:1307-1320.

33 Zhu J, Cote-Sierra J, Guo L, Paul WE. Stat5 activation plays a critical role in Th2 differentiation. Immunity 2003; 19:739748.

34 Schmitt E, Germann T, Goedert S, et al. IL-9 production of naive $\mathrm{CD}^{+} \mathrm{T}$ cells depends on IL-2, is synergistically enhanced by a combination of TGF- $\beta$ and IL- 4 , and is inhibited by IFN- $\gamma$. J Immunol 1994; 153:3989-3996.

$35 \mathrm{Lu} \mathrm{LF}$, Lind EF, Gondek DC, et al. Mast cells are essential intermediaries in regulatory T-cell tolerance. Nature 2006; 442:997-1002.

36 Nowak EC, Weaver CT, Turner H, et al. IL-9 as a mediator of Th17-driven inflammatory disease. J Exp Med 2009; 206:1653-1660.

37 Elyaman W, Bradshaw EM, Uyttenhove C, et al. IL-9 induces differentiation of $\mathrm{TH} 17$ cells and enhances function of $\mathrm{FoxP}^{+}$ natural regulatory T cells. Proc Natl Acad Sci USA 2009; 106:12885-12890.

38 Bauquet AT, Jin H, Paterson AM, et al. The costimulatory molecule ICOS regulates the expression of c-Maf and IL-21 in the development of follicular T helper cells and TH-17 cells. Nat Immunol 2009; 10:167-175.

39 Reinhardt RL, Liang HE, Locksley RM. Cytokine-secreting follicular $\mathrm{T}$ cells shape the antibody repertoire. Nat Immunol 2009; 10:385-393.

40 King IL, Mohrs M. IL-4-producing $\mathrm{CD}^{+} \mathrm{T}$ cells in reactive lymph nodes during helminth infection are $\mathrm{T}$ follicular helper cells. J Exp Med 2009; 206:1001-1007.

41 Zaretsky AG, Taylor JJ, King IL, Marshall FA, Mohrs M, Pearce EJ. T follicular helper cells differentiate from Th2 cells in response to helminth antigens. J Exp Med 2009; 206:991999.

42 Yu D, Rao S, Tsai LM, et al. The transcriptional repressor Bcl6 directs $\mathrm{T}$ follicular helper cell lineage commitment. Immunity 2009; 31:457-468.

43 Nurieva RI, Chung Y, Martinez GJ, et al. Bcl6 mediates the development of T follicular helper cells. Science 2009; 325:1001-1005.

44 Johnston RJ, Poholek AC, DiToro D, et al. Bcl6 and Blimp-1 are reciprocal and antagonistic regulators of $\mathrm{T}$ follicular helper cell differentiation. Science 2009; 325:1006-1010.

45 Zhu J, Min B, Hu-Li J, et al. Conditional deletion of Gata3 shows its essential function in $\mathrm{T}(\mathrm{H}) 1-\mathrm{T}(\mathrm{H}) 2$ responses. Nat
Immunol 2004; 5:1157-1165.

46 Tsuji M, Komatsu N, Kawamoto S, et al. Preferential generation of follicular B helper T cells from Foxp3 $3^{+} \mathrm{T}$ cells in gut Peyer's patches. Science 2009; 323:1488-1492.

47 Tan JT, Ernst B, Kieper WC, LeRoy E, Sprent J, Surh CD. Interleukin (IL)-15 and IL-7 jointly regulate homeostatic proliferation of memory phenotype $\mathrm{CD} 8^{+}$cells but are not required for memory phenotype $\mathrm{CD} 4^{+}$cells. $J$ Exp Med 2002; 195:1523-1532.

48 Purton JF, Tan JT, Rubinstein MP, Kim DM, Sprent J, Surh CD. Antiviral $\mathrm{CD}^{+}$memory $\mathrm{T}$ cells are IL-15 dependent. $J$ Exp Med 2007; 204:951-961.

49 Darrah PA, Patel DT, De Luca PM, et al. Multifunctional TH1 cells define a correlate of vaccine-mediated protection against Leishmania major. Nat Med 2007; 13:843-850.

50 Guo L, Hu-Li J, Paul WE. Probabilistic regulation of IL-4 production. J Clin Immunol 2005; 25:573-581.

51 Chang HC, Zhang S, Thieu VT, et al. PU.1 expression delineates heterogeneity in primary Th2 cells. Immunity 2005; 22:693-703.

52 Veldhoen M, Hirota K, Westendorf AM, et al. The aryl hydrocarbon receptor links TH17-cell-mediated autoimmunity to environmental toxins. Nature 2008; 453:106-109.

53 Suffia I, Reckling SK, Salay G, Belkaid Y. A role for CD103 in the retention of $\mathrm{CD} 4{ }^{+} \mathrm{CD} 25^{+}$Treg and control of Leishmania major infection. J Immunol 2005; 174:5444-5455.

54 Stephens GL, Andersson J, Shevach EM. Distinct subsets of $\mathrm{FoxP}^{+}$regulatory T cells participate in the control of immune responses. J Immunol 2007; 178:6901-6911.

55 Zhu J, Davidson TS, Wei G, et al. Down-regulation of Gfi-1 expression by TGF- $\beta$ is important for differentiation of Th17 and $\mathrm{CD}_{103}{ }^{+}$inducible regulatory T cells. J Exp Med 2009; 206:329-341.

56 Zhou L, Lopes JE, Chong MM, et al. TGF- $\beta$-induced Foxp3 inhibits $\mathrm{T}(\mathrm{H}) 17$ cell differentiation by antagonizing RORgammat function. Nature 2008; 453:236-240.

57 Yang XO, Nurieva R, Martinez GJ, et al. Molecular antagonism and plasticity of regulatory and inflammatory $\mathrm{T}$ cell programs. Immunity 2008; 29:44-56.

$58 \mathrm{Xu}$ L, Kitani A, Fuss I, Strober W. Cutting edge: regulatory T cells induce $\mathrm{CD} 4^{+} \mathrm{CD} 25$ Foxp $^{-} \mathrm{T}$ cells or are self-induced to become Th17 cells in the absence of exogenous TGF- $\beta$. J Immunol 2007; 178:6725-6729.

59 Koch MA, Tucker-Heard G, Perdue NR, Killebrew JR, Urdahl $\mathrm{KB}$, Campbell DJ. The transcription factor T-bet controls regulatory $\mathrm{T}$ cell homeostasis and function during type 1 inflammation. Nat Immunol 2009; 10:595-602.

60 Murphy E, Shibuya K, Hosken N, et al. Reversibility of T helper 1 and 2 populations is lost after long-term stimulation. $J$ Exp Med 1996; 183:901-913.

61 Wei G, Wei L, Zhu J, et al. Global mapping of H3K4me3 and $\mathrm{H} 3 \mathrm{~K} 27 \mathrm{me} 3$ reveals specificity and plasticity in lineage fate determination of differentiating $\mathrm{CD}^{+} \mathrm{T}$ cells. Immunity 2009; 30:155-167.

62 Lee YK, Turner H, Maynard CL, et al. Late developmental plasticity in the T helper 17 lineage. Immunity 2009; 30:92107.

63 Lexberg MH, Taubner A, Forster A, et al. Th memory for interleukin-17 expression is stable in vivo. Eur J Immunol 2008; 
38:2654-2664.

64 Oldenhove G, Bouladoux N, Wohlfert EA, et al. Decrease of Foxp $3^{+}$Treg cell number and acquisition of effector cell phenotype during lethal infection. Immunity 2009; 31:772-786.

65 Schoenborn JR, Dorschner MO, Sekimata M, et al. Comprehensive epigenetic profiling identifies multiple distal regulatory elements directing transcription of the gene encoding interferon- $\gamma$. Nat Immunol 2007; 8:732-742.

66 Hatton RD, Harrington LE, Luther RJ, et al. A distal conserved sequence element controls Ifng gene expression by $\mathrm{T}$ cells and NK cells. Immunity 2006; 25:717-729.

67 Lochner M, Peduto L, Cherrier M, et al. In vivo equilibrium of proinflammatory $\mathrm{IL}-17^{+}$and regulatory IL- $10^{+}$Foxp $3^{+}$ROR $\gamma \mathrm{t}^{+}$ T cells. J Exp Med 2008; 205:1381-1393.

68 Voo KS, Wang YH, Santori FR, et al. Identification of IL-17producing $\mathrm{FOXP}^{+}$regulatory $\mathrm{T}$ cells in humans. Proc Natl Acad Sci USA 2009; 106:4793-4798.

69 Komatsu N, Mariotti-Ferrandiz ME, Wang Y, Malissen B, Waldmann H, Hori S. Heterogeneity of natural Foxp $3^{+}$T cells: a committed regulatory T-cell lineage and an uncommitted minor population retaining plasticity. Proc Natl Acad Sci USA 2009; 106:1903-1908.

70 Wan YY, Flavell RA. Regulatory T-cell functions are subverted and converted owing to attenuated Foxp3 expression. Nature
2007; 445:766-770.

71 Zhou X, Bailey-Bucktrout SL, Jeker LT, et al. Instability of the transcription factor Foxp3 leads to the generation of pathogenic memory T cells in vivo. Nat Immunol 2009; 10:1000-1007.

72 Floess S, Freyer J, Siewert C, et al. Epigenetic control of the foxp3 locus in regulatory T cells. PLoS Biol 2007; 5:e38.

73 Hoffmann P, Boeld TJ, Eder R, et al. Loss of FOXP3 expression in natural human $\mathrm{CD} 4^{+} \mathrm{CD} 25^{+}$regulatory $\mathrm{T}$ cells upon repetitive in vitro stimulation. Eur J Immunol 2009; 39:10881097.

74 Zheng SG, Wang J, Horwitz DA. Cutting edge: Foxp $3{ }^{+} \mathrm{CD} 4{ }^{+} \mathrm{CD} 25^{+}$ regulatory $\mathrm{T}$ cells induced by $\mathrm{IL}-2$ and TGF- $\beta$ are resistant to Th17 conversion by IL-6. J Immunol 2008; 180:7112-7116.

75 Woltjen K, Michael IP, Mohseni P, et al. piggyBac transposition reprograms fibroblasts to induced pluripotent stem cells. Nature 2009; 458:766-770.

76 Takahashi K, Yamanaka S. Induction of pluripotent stem cells from mouse embryonic and adult fibroblast cultures by defined factors. Cell 2006; 126:663-676.

77 Yamada T, Park CS, Mamonkin M, Lacorazza HD. Transcription factor ELF4 controls the proliferation and homing of $\mathrm{CD}^{+} \mathrm{T}$ cells via the Kruppel-like factors KLF4 and KLF2. Nat Immunol 2009; 10:618-626. 